Parubchak Ivan, Smolinska Olesia

Ukraine

Joanna Marszałek-Kawa

Poland

\title{
Social Aspects of the Development of the Management Systems of Eastern European Universities in the Transformation Period
}

DOI: 10.15804/tner.2019.58.4.08

\begin{abstract}
The article describes the principles of cultural conformity, environmentalism and homeostasis as organizational in relation to the cultural and educational space of the university as a complex social system. On the basis of the analysis of the systemic changes that accompanied the newest stage in the development of universities in Eastern Europe (from the mid 1980s up to now) a periodization of this stage was completed. Each of the stages is characterized by a description of the above-mentioned organizational principles of work, the transformations of key characteristics of social governance and the overall logic of their development. The forecast of transformational changes for the nearest future in the context of social aspects of the development management of universities in Eastern Europe is made.
\end{abstract}

Keywords: Eastern Europe, social management, university, cultural and educational space, management, development, periodization, cultural conformity, environmentalism, homeostasis

\section{Introduction}

Modern tendencies in social development are characterized, first of all, by a vagueness, a considerable degree of generalization, and the absence of specifically formulated goals, of which the main is to secure a way of existence for mankind 
today, thanks to which the future will be possible and prosperous. Taking a triune concept of sustainable development, comprising economic, social and environmental factors, which together ensure sustainable development, a university is one of the institutions within higher education in which all three components operate simultaneously. The problem of implementing systemic approaches to managing the sustainable development of higher education can be viewed from both the subject/object and instrumental (both research and management) perspectives.

More people are going to university every year. There is a strong resistance to the notion that the university as a collegial and critical institution is dead, among academics as well as among the broader public. In the past, universities showed dissent, a civil courage conscience, but now instead they have become little more than pseudo-businesses, which render them incapable of remaining critical, or independent (Izak et al., 2017).

Higher education has been evolving rapidly to react to fast changing demands and needs. A new stage of institutional change in education usually begins with the adoption of new legal standards. Demographic changes affecting a large number of students have to be taken into consideration when designing higher education policies and goals. Many countries are concerned about the decreasing number of young people and how such changes will influence higher education participation and funding. The twentieth century aimed to outline the delineation of the national higher education systems of the post-communist period. This was linked in the post-Soviet states to the results of transformations within the Bologna Process, and in other post-communist countries, rather to its accompaniment and stabilization of national higher education systems. For example, this is happening in Poland, which is a leader in the field of higher education in Eastern Europe.

The components of the higher education system are elements that determine both the quality of the institution as a whole and its organization. This is in line with the concept of sustainable development, in particular its social component of human-centrism, as a key foundation of global education policy and the principle of educational activity. This approach is the key to achieving internal social and inter-generational justice, thus ensuring the stability of social and cultural systems on the basis of principles of pluralism and tenacity, and it defines the main features of social governance in higher education.

The transformations taking place in university education in Eastern European countries have several prerequisites: globalization processes, digitization and postmodern virtualization of social existence. For Ukraine, Belarus, Russia and Moldova, it is also possible to add the difficult socio-economic conditions that are underpinned by serious political crises. The uncertainty of circumstances, the 
current social, economic and political situation in Eastern European countries, on the one hand, complicate the forecasting, and on the other actively stimulate it in order to find ways to solve urgent problems. Therefore, conducting multidisciplinary research using a systemic approach to the social management of higher education, including university education, is relevant.

It is noted above that the problem of the implementation/exploitation of the systemic approach is the problem of the subject / object. In addition, the key change of system elements in higher education and the principle of preserving the stability of the system are highlighted. Hence, the purpose of this study is to identify a possible object and to apply the systemic approach to carry out a retrospective analysis of its functioning and development, to identify a variant of further evolution, and to characterize the approaches of social management in higher education.

\section{Status of Scientific Study of the Problem}

The analysis of the scientific elaboration status of the problem shows that various scientific disciplines often determine authors' considerations on higher education; at the same time there are studies of integrated nature, as well as those whose results can be applied to the studied object. In particular, for the purposes of this article, the works of the following scientists were explored: V. Bekh, D. Bell, H. Boer, B. Clark, M. Czerepaniak-Walchzak, J. Freeman, M. Hannan, M. Izak, M. Kostera, D. Manuel-Navarrete, O. Smolinska and M. Zawadzki. Despite the authors' attention to the concept of university and university education, their understanding of the problem of systemic organizational analysis of the principles of Eastern European universities functioning during the latest period of transformation (1990-2018), from the philosophical, managerial, pedagogical, cultural, sociological positions, and application of the relevant principles of social management, remain unresolved.

\section{Selecting the Object for System Analysis}

The problem of the object and the study of the characteristics of the system, which will enable us (as efficiently as possible) to determine the forms, methods, and mechanisms of universities which function as elements of educational systems in Eastern Europe, can be solved in several ways. The first, and most obvious, is the 
analysis of the university (classical or specialized) as an organization (institution). The second is the analysis of an organization in its cultural and educational space. Choosing the first analysis is more in line with the economic component of the concept of sustainable development, which is more predominant in social, political and scientific discourse. Choosing the second method is oriented more towards the social component and, in addition, concerns the internal mechanisms of activity, and therefore, it is of prognostic importance for management. For these reasons, as the object of systemic analysis the cultural and educational space of university was selected as a special type of local chronotype. This arose as a result of the activities of individual and collective subjects in acquiring professional engagement, and, in turn, defines the parameters of both as this reality, and so as an activity of subjects in its acquiring and organizing (Bekh, 2000). Structural reforms aim to change the landscape of higher education: incremental changes unfolding over longer periods of time and reforms targeting other aspects of higher education. Structural reforms aim at horizontal differentiation, that is, transformation of the function of different types of higher education institution (Boer et al., 2017).

\section{Principles of the Organization of the Cultural and Educational Space of a University}

Three leading principles of organizing the cultural and educational space of a university ensure effectiveness : the principle of cultural conformity, the principle of environmentalism and the principle of homeostasis (Clark, 2003). The separation of these principles is made for reasons of functionality: the principle of cultural correspondence defines and regulates the content of cultural patterns; it is a specific "shell" of the cultural and educational space and can be characterized as rigid or plastic, with varying levels of penetration and different configuration of apertures that, in fact, connect the environment with the internal content of the university, its system of values, transparency and so on. Ideally, the cultural environment of a modern university should be characterized as variable, dialogical, tolerant, reflexive, spiritually and culturally rich, capable of self-creation, self-genesis, self-reformation and self-denial (Bell, 1976).

The principle of environmentalism functionally links the cultural and educational space of the university with the external environment; it is a characteristic system that determines the type of university as an organization (closed, open, natural, artificial, etc.). If cultural conformity is, metaphorically, a shell, then environmentalism is the type of "input-output" to the system, which can, accordingly, 
be stable and orderly (a closed system); with variable input-output parameters (an open system); or responsive, adaptive "input-output" (a natural system). It is governed by the principle of a quasi-natural object, which purposefully, evolutionarily and gradually develops and functions according to its own laws, which ensure its viability (survival). In this regard, there is a continuing scientific discussion about the contribution of educational institutions to artificial communities in the light of the purpose of creation, a center of control, hierarchical structure and vertical communications, lack of redundancy (outweighing the effort over the result) and purposefulness of activity. The question can indeed be discussed, since the approaches taken at the present stage are social approaches, aimed at creating the conditions for the transition of universities from artificial to natural organizations, which has been happening gradually since the 1980s.

Therefore, the cultural and educational space of the university can be analyzed as an ecosystem with a complex structure that resides in the system of population and ecological niches. A population-ecology perspective on organization-environment relations is proposed as an alternative to the dominant adaptation perspective (Hannan, 1977). Socio-cultural and ecological subsystems are not organizationally equivalent, because human agents shape social organization by making reflexive and relatively autonomous decisions about reproducing, or challenging social rules (Manuel-Navarrete, 2015).

The principle of homeostasis, which, in fact, characterizes the cultural and educational space of the university as a natural system, and is capable of preserving the relative dynamic constancy of the parameters of composition and functions, acts as a counterbalance mechanism to external influences. Partly by the effect of this principle can inertia in the university's cultural and educational space as regards change be explained; a tendency to increase in closeness, commensurate with the increase in the power of external influences; some "encapsulation" of values; the formation and consolidation of traditions which are not always productive but always strong. Balancing the effectiveness of the principle of homeostasis as a guarantor of the development of the organization, its collectiveness of goals (in the homeostatic mode) and the basis of formation and preservation in its own organic integrity (in the homeostatic mode), ensures the transformation of social (national, political, etc.) ideas into a phenotype of social organism, in our case the cultural and educational space of the university.

Therefore, the cultural and educational space of the university can be characterized as a complex, active, natural open system, the key feature of which is the implementation of bilateral communications; for cultural conformity - its content, and environmentalism - a positive type of connection with a beneficial conno- 
tation, which allows the possibility of external influence, and for the principle of homeostasis - a positive type of communication with a negative meaning.

\section{Periodization of Systemic Changes in Higher Education in the Post- Soviet Countries in Eastern Europe}

First of all, it should be noted that the formation of the cultural and educational space of universities in the latest stage of development is connected with formation and development in different periods, but for the analysis we take into account only the Soviet period and only those educational institutions that were functioning as institutions during this period. We put more emphasis on system characteristics than on the features of the current specialization of the university (pedagogical, medical, technical, etc.), which, after all, also affects the object, but is not the objective of this research. In order to characterize systemic changes in the organization of the cultural and educational space of the university, it is advisable to determine their stages. M. Czerepaniak-Walczak believes that the integrality/incompleteness of reforms and their typologies should be taken into account during the analysis, as well as the source of the reform initiative (whether they stem from transnational educational policies, etc. or are the result of national decisions) (Czerepaniak-Walczak, 2019). We agree with this, but let us add that the characteristics of the agents and the essence of the changes are also important.

Based on the analysis of documents and historical facts, we consider it appropriate to divide the period of development of profession-oriented universities in Eastern Europe in the twentieth century into four stages:

- Stage I - from the establishment (in fact - from the second half of the 1940s) of institutions to 1984 (the beginning of the last Soviet educational reform, which introduced a variable component in the curricula for both secondary and higher education). It is appropriate to call this a period of certainty;

- Stage II - the second half of the 80 s - the first half of the 90s. Its key feature was the large number and variety of external influences. The "open door" metaphor is appropriate for this period;

- Stage III - mid 90s - early 2000s. The main process was institutional reorganization: institutes were transformed to the status of classical and specialized universities. This is the period of the university; 
- Stage IV - from 1999 (state parties signing of the Bologna Declaration) until 2010, when the reform of national higher education systems was to be completed - a new period of stabilization and certainty, autonomisation of universities;

- Stage V - since 2010, still going on. Reinforcing external influences. The second period is the "door opening".

In this stage, the prognosis for the next period (re- or deinstitutionalization) is clearly visible, as well as the tendency for the length of the periods to reduce, which is peculiar for the evolutionary process. It is necessary to note that changes in legislation are not synchronous with managerial and meaningful changes in internal interactions within both the European educational space and within each national education system. Therefore, the chronological framework of periodization is conventional.

\section{Characterization of the Effectiveness of the Cultural Conformity, Environmentalism and Homeostatic Principles at Different Stages of Development of the Cultural and Educational Space of Universities}

In the beginning of the article we describe the way in which the principles of organizing the cultural and educational space of universities operate. In this section we describe their action at different stages of change.

The first stage (from the formation (in fact, from the second half of the 1940s) of institutions to 1984) occurred as a period of formation, stabilization and "solidification" of the system. Since we are also talking about the cultural aspect, it is appropriate to mention $\mathrm{O}$. Spengler and his relation of culture and civilization as a transition from creativity to a mechanism. The cultural and educational space of the institutions of the time did indeed resemble a well-established mechanism by a type of efficiency. In particular, the principle of cultural responsibility, which functioned not at the level of institutions (especially - not at the level of establishments), but at the level of the education system, allowed only verified forms, clearly and definitively regulating the activities of its elements. Therefore, the style of government was authoritarian, both in the educational system and at the level of institution.

The principle of environmentalism could only work in certain configurations of the valve of admission of regulatory influence and release of its result. The principle of homeostasis also worked at the system-wide level, maintaining 
certain configurations (forms, types, ways of interaction of the system with the surrounding environment). Consequently, the cultural and educational spaces of institutions of higher education did not exhibit features of the system; instead, all higher education could be metaphorically described as a nut with a solid, low-pass, non-plastic sheath. Some of the "protectors" of this system still exist and operate now in separate cultural and educational spaces partly as myths, sometimes as a specificity of management, but still, always, of bureaucracy. The educational reform of the USSR in 1984, through the introduction of the variational component in curricula, influenced the cultural context (its ethnic, regional, and other elements), which also led to a change of principle positions, both in the content of education and in the content of the subjectivity of culture (teachers innovators, new didactic and educational principles, etc.). At last, this led to the beginning of the second stage.

Changes in the second stage (the second half of the 80s - the first half of the 90s) in the organization of cultural and educational space of universities, which began with the opening of the system, using the nut metaphor, occurred as it splitsimultaneously, in many places at the same time, and in a short time (compared to the previous period). Therefore, the principle of cultural conformity ceased to be a reliable shell and filter. The principle of environmentalism, which acted mainly as a tolerance of different influences on the system, was a point of breach. The principle of homeostasis functioned as a natural protection for elements that had lost their outer shells, managed internal integration relationships, and manifested itself, not as a power, but as an aggressive energy for change, its crushing criticism an active influence on agents of change in the cultural and educational space in order to eliminate them (often through discreditation, or squeezing). So, the second stage ended with the destruction of the previous system, within which the preconditions for several new stages took place (institutions capable of acting independently, building their own culture, which were in the future to become classical universities; institutions capable of functioning as elements of another system - universities with specialization; the so-called profession-oriented). At this stage, the role of leaders of educational change became noticeable, and the type of management became adaptive.

The third stage (the mid-90s - early 2000s) was in line with the changes which started in the previous stage: based on institutes classical, specialized universities appeared, and institutions such as institutes and academies remained. An appropriate effectiveness was also shown by organizational principles: as far as universities were concerned, cultural correspondence formed their own shell (history was written, internal traditions were formed). Because of this the prin- 
ciple of environmentalism became selective (only those influences that were in conformity with the existing cultural and educational principles of activity were allowed, others were ignored). The principle of homeostasis operated from inside the cultural and educational space of a particular educational institution, often following the model of "trench warfare" to give the new system the opportunity and time for stabilization. This is the period of the emergence of new scientific schools, as well as other traditions that have increasingly given the educational and scientific culture of the characteristics of a clan. Criticism of this period must take into account the objective circumstances and conditions for the "closure" of new systems, which, in the next period, became the culturally determined basis for the autonomy of universities. A period of managing actions and people, not goals and social connections.

The fourth stage (from 1999 to 2010) can be called the stage of stable development of universities (despite the simultaneous reduction in the total number of universities). These "grew" during the second period, when the birth rate was still quite high (for example in Ukraine in 1988 - 1.7 per woman versus 1.0 in 1997 (The population of Ukraine), and was cherished by the education of the same second period. Traditional national and cultural values, including education, were of equal focus with the current declared values of the cultural and educational space of universities: increased availability of higher education through the introduction of equal conditions of entry by means of centralized testing in Belarus, a single state examination in the Russian Federation, and external, independent testing in Ukraine, and commercialization. The principles of organization of the system of the cultural and educational space acted in a similar way as in the first period, with the significant difference, not at the level of the educational system, but at the level of universities, (the system of which was formed in the previous stage), that they began to show self-destructive tendencies, due to overly rigid organization (at first periodically), a limited supply of "fresh blood" (they have the tendency to employ their own graduates who do not require enculturation efforts), and the "stitching" together of ambivalent values, e.g. education as a vocation and as a commodity, science as an intellectual and commercial activity, etc. If an open natural system allows such combinations to be manifested, for example, in the laws of evolution, then social systems that have arisen and formed in the conditions of limited time and material resources naturally come to the next stage, which is violation of sustainability and integrity.

We claim that the next stage, which is now underway, will be characterized, in the first place, by the destruction of the shell of cultural correspondence (despite its severity, this is not as massive a change as at the turn of the 80-90s, there- 
fore, there is no need to be afraid of complete collapse of the whole system of higher education, the expectation of which is one of the myths of the cultural and educational space, generated by the action of the principle of homeostasis), and secondly, the effect of environmentalism is changing its orientation from being internally socially oriented (often ideologically, or politically conditioned) to being externally oriented (setting-up horizontal links with foreign universities). Again, very often this is generated by the action of the principle of homeostasis, a thesis about the destruction of national-cultural traditions in higher education, but without specification. At the same time, from the standpoints of the principles analyzed, the complexity of the current period lies in the subtlety, or absence, of the organizational "fat layer" of the profession-oriented universities (hence the weakness of the influence of cultural conformity), the need to generate new values and "stitch" them together with the existing ones (formed and established in previous periods), the simultaneity of the processes of the coming of subjectivity and their objectification in the new organizational configurations of the cultural and educational space of the university, etc.

\section{Peculiarities of Social Management in Higher Educational Institutions in Forming the System of Student Values at the Current Stage}

The social component of pedagogical technologies is the main link in social management, because the success of teachers' activity depends mostly on the coherence of their work, the coherence of actions, the understanding and acceptance of the goals and objectives by each member, the significance and specificity of their activities; the role, place, and opportunities for their realization. On the other hand, today every teacher, as well as administrator in education, must have competences in democratic communication, because this is at the heart of the pedagogy of cooperation and involves the implementation of teacher's preferences through student acceptance of information. The social governance model should provide a social order that defines the structure of the state educational standard. Socio-governance includes open, closed and mixed social governance. Open social management involves the control and correction of the process of organizing education, with a usuall end result: the student (teacher, employee), acting strictly by instruction, should always get the right result; there are no errors in the intermediate stages of the task, only standard difficulties can be eliminated. 
Closed social management requires constant monitoring (control) of every element of educational activity and the main parameters of its quality, as well as the control and correction of educational activities deviating from their predefined values (such as cultural patterns). This kind of management also requires the existence of a direct link between the subject and the object of management, which is intended to convey the relevant instructions. Another required element is the availability of feedback about the results of educational activities (including the results of educational interactions, the effectiveness of management initiatives, and the integrity and content of characteristics of the cultural and educational space). Of course, a closed social management is much more effective, but it requires a lot more effort and time. Thus, social management is developed at the various stages of the university, in both open and closed environments. It developed at the second, third and fourth stage of university in the former type of environment, while at the first, modern stage in the latter one). The holistic view of the analyzed criteria of cultural conformity, and the principles of homeostasis and environmentalism suggest that mixed social governance should be applied. Organizational and pedagogical factors and conditions that ensure the effectiveness of any educational / pedagogical technology, including cultural-oriented technologies for the formation of socio-spiritual values, include: material and technical resources; scientific and pedagogical support; system of methods of organization and functioning of approaches of social management, both by activity of single subjects (students, teachers, administrators of higher education), and collective subjects (the cultural and educational space of the university). A student as a living being, a free and spiritual person, may also be the focus of educational communications for social management; and the university (its cultural and educational space) as the subject of a culture of education where values are objectified. A common feature of both entities is their need for self-development in the inner world. This creates the preconditions for the development of activity, initiative, creativity, and engagement. Criteria for differentiation and individualization of the educational process with relation to the subject-student are peculiarities of the course of cognitive mental processes; needs, value attitudes, and personality characteristics. The subject-university in the aspect of social management also has individual characteristics, which are determined by the peculiarities of its history, culture, and which materialize in artifacts (social facts, myths, etc.).

There is a dynamic connection between the two subjects/objects of social management (the student and the cultural and educational space of the university). As a result, the individual characteristics of the student, in the real organization of 
student-centered educational interactions, are objectified into the content of social facts of the university's cultural and educational space (success stories, achievements, failures, difficulties); and social facts, myths and the rest are reproduced in educational communications in the space of university, filling general and specialized competencies with real content, and creating the added educational value of a university education of each student in particular.

Therefore, in the social management of educational interactions in university education is pledged the security of improving the quality of education on an innovative basis, on the basis of modern scientific and pedagogical support of the process of obtaining education; and implementation of competency approaches.

The effectiveness of social management of the personality development of a student, and/or development of the university, is multifactorial and determines the effectiveness of the social governance model as a whole. This eliminates the exaggeration of the weight of individual methods of work, teaching and upbringing, or exaggeration of the role of methodological developments that do not take into account the specific conditions and individual abilities of students: that is, rationality, reasonableness, a sense of measure, unity of the physical, world-view, spiritual and intellectual development of the young personality. Higher education in Eastern Europe is now at different stages of transition from classical to post-classical methodological approaches (post-Soviet states are still very close to classical), so implementation of the principles of social governance contributes to the development of subjectivity, respectively via competency- and culturally-oriented approaches.

With adequate social management in the structure of higher education institutions, the student can achieve significant educational results, and engage in a continuous process of self-improvement and self-education. The introduction of the principles of social management at university contributes to the development of its cultural and educational space, focusing on internal and external interactions on institutional development, increasing capacity, improving the quality of human resources, and increasing the added educational value.

\section{Conclusions}

For the purpose of analysis, with the aim of reviewing the past and making a forecast, the cultural and educational space of university was chosen as a systematic formation. The three main principles of organizing the cultural and edu- 
cational space of universities are described: principles of cultural correspondence, environmentalism and homeostasis. Periodization of the development of Eastern European higher education was carried out, in view of systematic changes in the organization of the cultural and educational space of universities. According to the stages distinguished, key systematic features of the cultural and educational space of developing universities in Eastern Europe, including the post-Soviet region, are characterized and a forecast is made for the near future. The character of transformational changes in social aspects of development management of universities in Eastern Europe, predicted for the coming period, is substantiated.

Prospects for further research on this topic are to study the individual characteristics of a university's cultural and educational spaces, to specify the values circulating in them, to identify the signs of the closest public institutional environment, to determine the principles of managing organizations and the values which are under conditions of constant transformation.

\section{References}

Bekh, V.P. (2000). Natsionalnaya ideya: smyisl i mehanizm deystviya [The national idea: the meaning and mechanism of action]. Naukovi pratsi istorychnoho fakultetu Zaporizkoho derzhavnoho universytetu, 11. Retrieved from: http://istznu.org/dc/file.php?host_id=1\&path=/page/issues/11/./beh.pdf.

Bell, D. (1976). The coming of post-industrial society: a venture in social forecasting. Reissue edition. New York: Basic Books.

Boer, H.F., File, J.F., Huisman, J.F., Seeber, M.F., Vukasovic, M.F., \& Westerheijden, D.F. (2017). Policy Analysis of Structural Reforms in Higher Education. Processes and Ourcomes. Cham: Springer International Publishing. doi: 10/1007/978-3-319-42237-4.

Clark, B.R. (2003). Sustaining change in Universities: Continuities in case studies and concepts. Tertiary Education and Management, 6(2), 99-116.

Czerepaniak-Walczak, M. (2019). Education reform - cui bono? The New Educational Review, 55, 185-194. doi: 10.15804/tner.2019.55.1.15.

Hannan, M., \& Freeman, J. (1977). The Population Ecology of Public Organizations. American Journal of Sociology, 82(5), 929-964. doi: 10.1086/226424.

Izak, M., Kostera, M., \& Zawadzki, M. (2017). The Future of University Education. Springer International Publishing. doi: 10/1007/978-3-319-46894-5.

Manuel-Navarrete, D. (2015). Double coupling: modeling subjectivity and asymmetric organization in social-ecological systems. Ecology and Society, 20(3): 26. http://dx.doi. org/10.5751/ES-07720-200326.

The population of Ukraine. (n.d.). Retrieved from: http://database.ukrcensus.gov.ua/ukrcensus/Dialog/statfile1_c_files/pasport.files/pasport/80/80_03.htm. 